\title{
Everything You Need to Know to Run a Successful Clerkship
}

\section{Guidebook for Clerkship Directors, Fifth Edition. By Bruce Z. Morgenstern (editor), Alliance for Clinical Education; Gegensatz Press; North Syracuse, New York; 2019; ISBN: 978-1-62130-727-3; pp. 500; $\$ 59.95$ (paperback)}

\author{
Mary K. Morreale ${ }^{1}$ (D)
}

Received: 25 July 2019 / Revised: 25 July 2019 / Accepted: 28 July 2019 / Published online: 12 August 2019

(C) Academic Psychiatry 2019

There are many challenges to running a successful clerkship for medical students, particularly for newcomers to the task. What is the best way to update the curriculum? How should one manage the accreditation process of the Liaison Committee on Medical Education (LCME)? Are there tactics for approaching educational scholarship? Given the breadth of responsibilities involved, it is important to seek guidance in the process. The fifth edition of The Guidebook for Clerkship Directors, from the Alliance for Clinical Education (ACE), is designed to be part of that support and is an essential text for any faculty involved in the administration of undergraduate medical education.

Containing 32 chapters written by experts across medical specialties, the Guidebook for Clerkship Directors covers a comprehensive list of topics. Although the text is not formally structured according to content area, the chapters in the Guidebook for Clerkship Directors can be broadly classified as relating to the student and curriculum (e.g., nurturing medical professionalism, instructional methods and strategies, remediation for struggling learners), residents and faculty (e.g., development of residents as teachers, evaluation of clerkship teachers, faculty development), and administrative issues (e.g., evaluating the clerkship, day-today management, the role of the clerkship administrator). Although this guide is intended for every type of clerkship director, there is nothing in this book that would not apply to psychiatric faculty in this role.

Even though the Guidebook for Clerkship Directors is considered a "guide" and "can not replace being mentored, networking and personal investigation" (p. xi), it does an excellent job of synthesizing relevant information. For example, in the chapter

Mary K. Morreale

mmorreale@med.wayne.edu

1 Wayne State University, Detroit, MI, USA titled "Instructional Methods and Strategies," the author defines Bloom's Taxonomy as a framework for both planning a teaching session and deciding what method of instruction to use. A discussion of the positive and negative aspects of large group learning follows, with suggestions for enhancing this type of activity. Various types of small group instructional methods are briefly described such as problem-based learning (PBL), team-based learning (TBL), case-based learning (CBL), and role-play. The chapter concludes with several paragraphs on how teaching differs in ambulatory and inpatient settings and describes both the "One Minute Preceptor" and the SNAPPS (Summarize, Narrow, Analyze, Probe, Plan, Select) models as means to enhance efficacy. After finishing this chapter, the reader would certainly have a good compass for exploring textbooks and educational journals.

How does this book differ from the previous edition, published in 2012? New chapters are presented on lifelong selfdirected learning, promoting wellness, interprofessional education, the science of health care delivery, legal issues faced by clerkship directors, medical ethics, and the overlap between preclinical and clinical education. Many new authors are introduced, leading to "significant rewrites" (p. viii). In addition, chapters now contain take-home points on the first page. The Guidebook for Clerkship Directors is available in softcover, with several e-book options also at a reduced price.

Although there are some spelling errors and acronyms are not always properly defined, these issues do not get in the way of the utility of this book. The Guidebook for Clerkship Directors is definitely worth the read and would be of benefit to both new and seasoned clerkship directors in any field of study.

\section{Compliance with Ethical Standards}

Disclosure The author states that there is no conflict of interest.

Publisher's Note Springer Nature remains neutral with regard to jurisdictional claims in published maps and institutional affiliations. 